\title{
Spontaneous nephroblastoma in a hatchery rainbow trout Oncorhynchus mykiss
}

\author{
J. ̌̌ehulka
}

Research Institute of Fish Culture and Hydrobiology, Vodñany, Ostrava Station, 70200 Ostrava, Varenská 51, Czech and Slovak Federal Republic

ABSTRACT. Finding of a nephroblastoma in a juvenile rainbow trout Oncorhynchus mykiss is described; the total body length of the fish was $140 \mathrm{~mm}$ and weight $45 \mathrm{~g}$. The fish had been fed dry pellets. The tumour was of a considerable size and weight ( $28.8 \%$ of the fish's body weight) which caused lordosis of the host's spine. The tumour's expansive growth pushed the internal organs deep into the abdominal part of the body. The tumour structure comprises 2 components: epithelial and mesenchymal. Its epithelial parts prevailed, no other structures (myeloblastic, neuroblastic and cartilaginous) being present. The tumour was a demarcated formation with no haemorrhages, no necroses and metastases that would penetrate into the organs. No haematopoietic tissue and no melanin were detected in the neoplastic tissue

Findings of nephroblastoma in a hatchery-reared rainbow trout Oncorhynchus mykiss are reported by Ghittino \& Dalforno (1971), Harshbarger (1972, 1973-1980) and Odense et al. (1973). Nephroblastoma experimentally induced in rainbow trout fed a diet containing dimethyl nitrosamine (DMN) and radioiodine is described by Ashley (1970). According to Harshbarger (1972), the induced lesion appeared to grow faster and to be more anaplastic than cryptogenic in the case he described.

Nephroblastoma is a name given to an embryonal miscellaneous tumour of the kidneys, histogenetically derived from nephrogenic blastoma. Sometimes it is called Wilms' tumour, embryonal nephroma or renal adenosarcoma. In this paper I describe a case of nephroblastoma in a rainbow trout of a commercial stock fed dry pellets. In the 20 yr period of preventative diagnosis of the state of fish health in Czechoslovakia, this is the first finding of a nephroblastoma whose etiology is of a spontaneous nature.

For histological examination, tissue samples of the tumour and organs (kidney, spleen, liver, stomach, gut, brain, muscle and gills) were fixed in $10 \%$ neutral formalin and the paraffin slices were stained with haematoxylin and eosin (H\&E), by the PAS method (periodic acid Schiff's reagent), by means of the Masson green trichrome, and after Gömöri's method).

One paraffin block of a kidney growth and 2 black and white photographs were submitted to the Registry for Tumours of Lower Animals, Smithsonian Institute, Washington, D.C., USA. They were accessioned as RTLA 3737.

Gross description. An age $1+$ rainbow trout Oncorhynchus mykiss, $140 \mathrm{~mm}$ long and weighing $45 \mathrm{~g}$, was observed swimming in an abnormal position on its side near the bottom. When caught, the fish was found to have a serious lordosis of the spine and a greatly enlarged abdomen (Fig. 1). Autopsy revealed a large,
Fig. 1. Oncorhynchus mykiss. Lordosis of the spine in the rainbow trout with marked excavation caused by the weight of the tumour

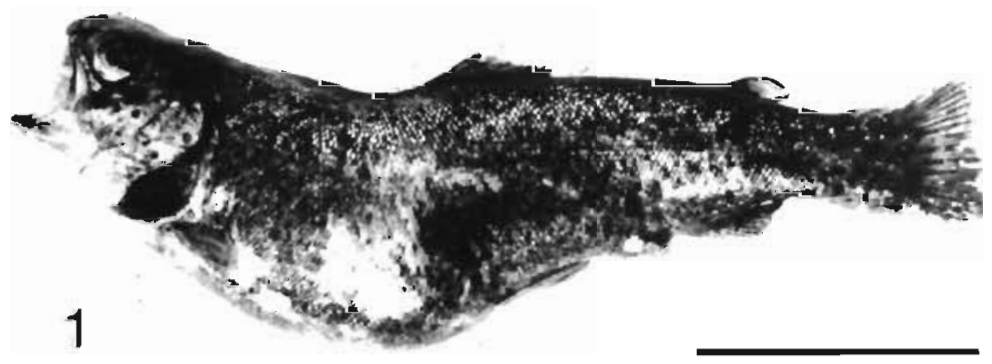

$40 \mathrm{~mm}$ 


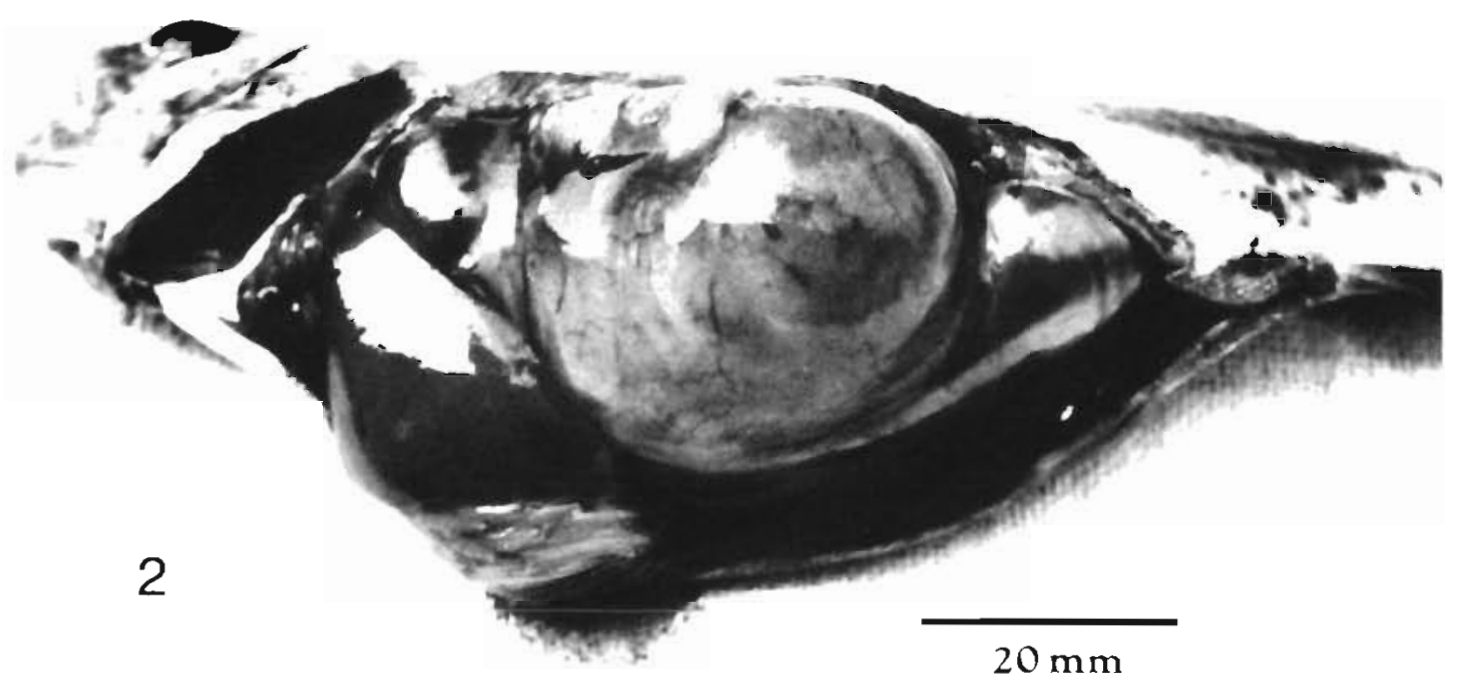

Fiy. 2. Oncorhynchus mykiss. Large, globose, expansively arching tumour

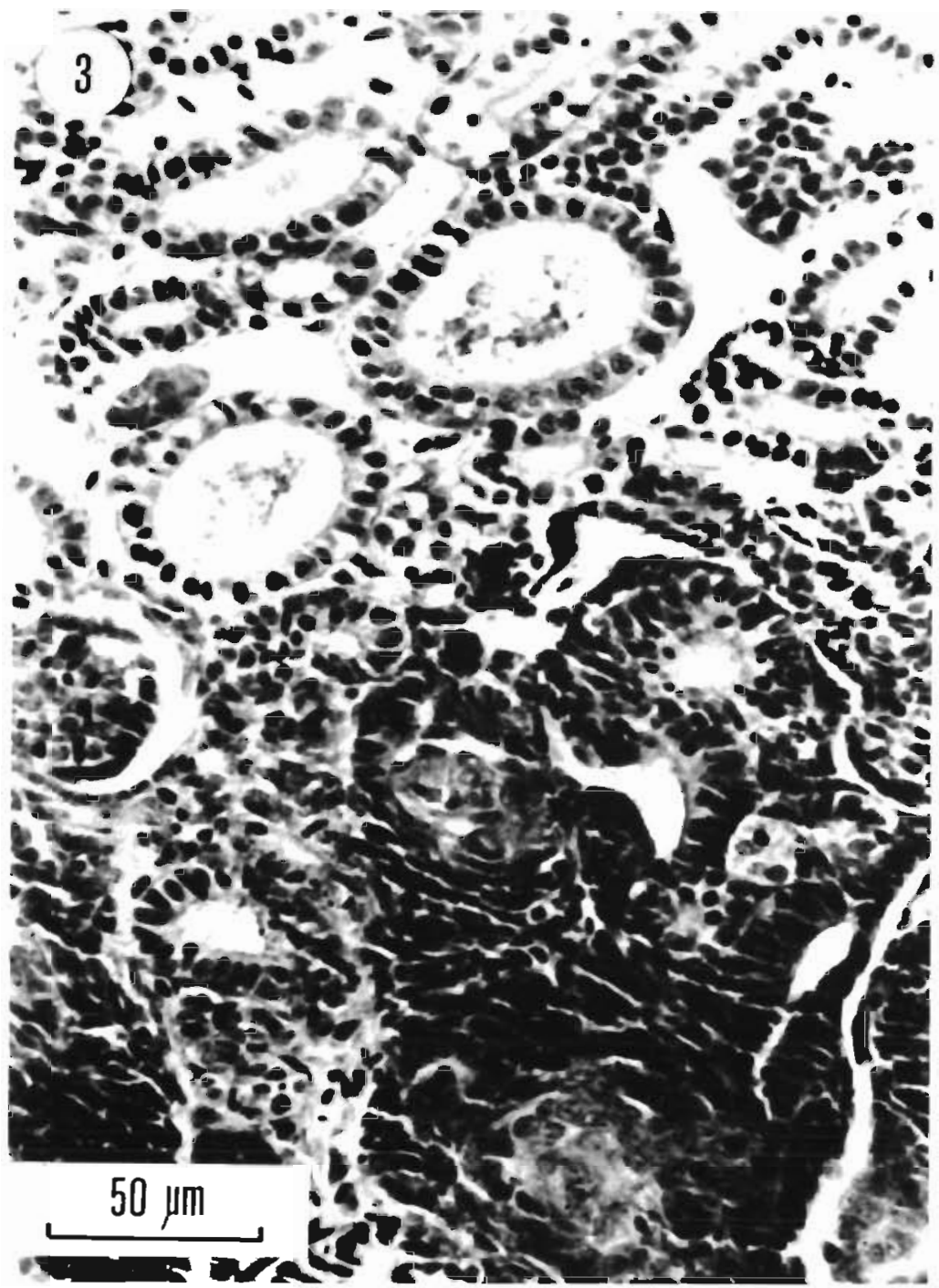

Fig. 3. Oncorhynchus mykiss. Proliferation of the tumour into the tubular structures of the pulp (Masson's green trichrome, $\times 200$ ) 
rounded and greyish-red tumour (Fig. 2), growing from virtually the entire kidney, with the exceptions of small bands of renal tissue in the head and posterior kidney. The tumour considerably deformed and compressed the swim bladder which, due to the expansive growth of the tumour, was squeezed deep into the abdomen. The tumour was well demarcated, separated from the surrounding organs and showed no signs of proliferating into them. The weight of the tumour was $13 \mathrm{~g}, 28.8 \%$ of the fish's body weight. No haemorrhages were observed on the tumour or on the organs.

Microscopic description. There were 2 basic components of the tumour structure: epithelial and mesenchymal. The prevailing epithelial components were at different degrees of development. Besides the comparatively well-developed and regular structures of the tubules, glandular formations at a lower degree of differentiation were seen with the development of small cysts and adenopapillary formations passing into mesenchymal formations (Figs. 3 \& 4). The majority of these were longitudinal and fascicular. Some tubules, altered by the tumour, were slightly cystically dilated and the epithelium sent out papillary formations into their lumens (Fig. 5a). In some places the tubules were non-luminized and entirely altered by streaks of tumorously changed epithelia. There are hints of the presence of structures reminiscent of a glomerulus (Fig. 5b). Tissue samples stained using the special collagen staining technique showed some collagen fibres in the interstitium, mostly in the proximity of the mellow tubular structures. The cytological differentiation of the abortive sectors was indistinct, with the presence of thinly distributed mitoses. The kidney was infiltrated by the tumour with no trend of proliferation into the surrounding tissue and no metastases in the other organs tested.

Our findings correspond with the description of a nephroblastoma (adenosarcoma) of the kidney, which
Fig. 4. Oncorhynchus mykiss. Nephroblastoma with structures of mesenchymal (M) (sarcomatoid) differentiation (Masson's green trichrome, $\times 400$ )

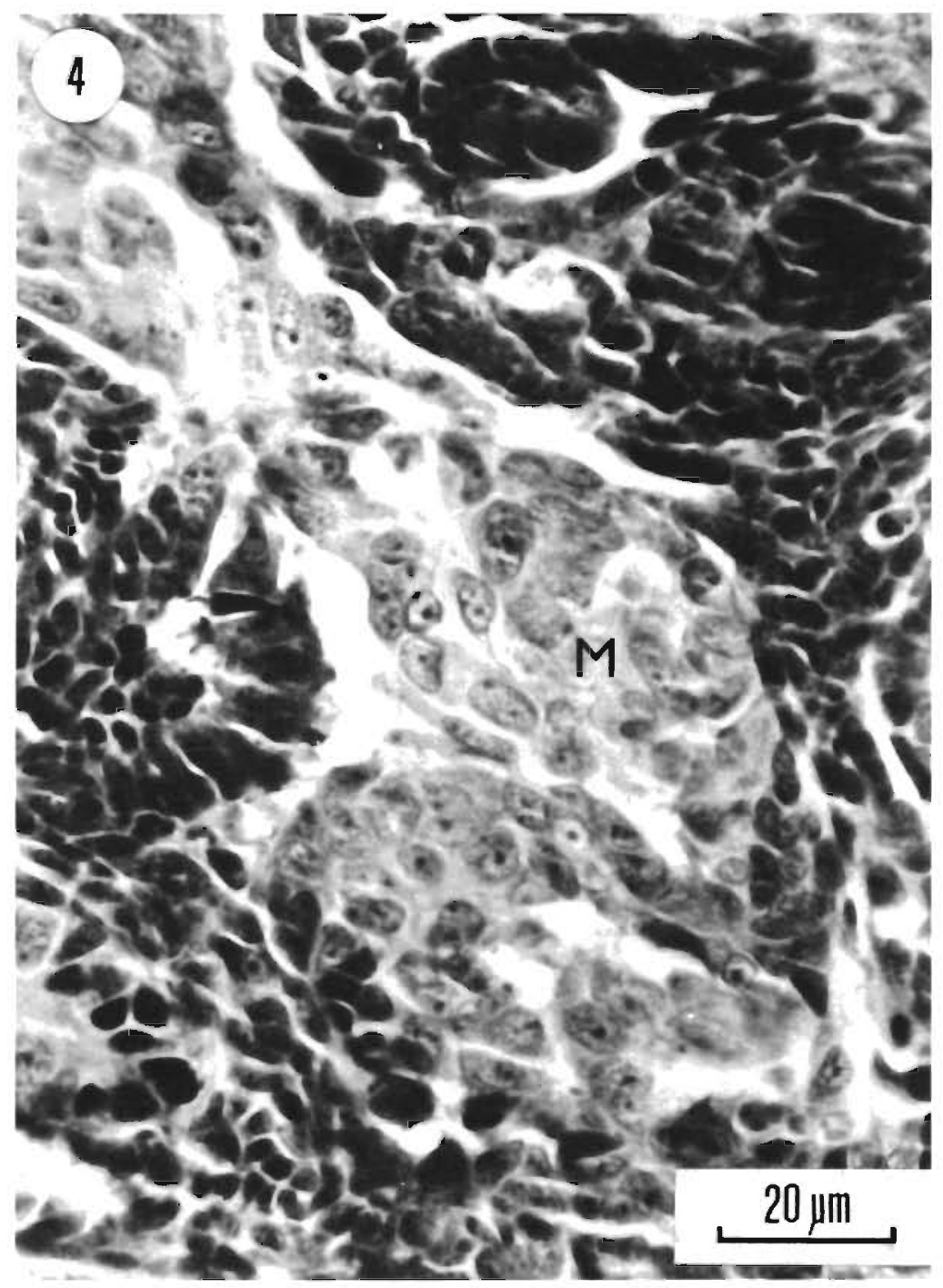



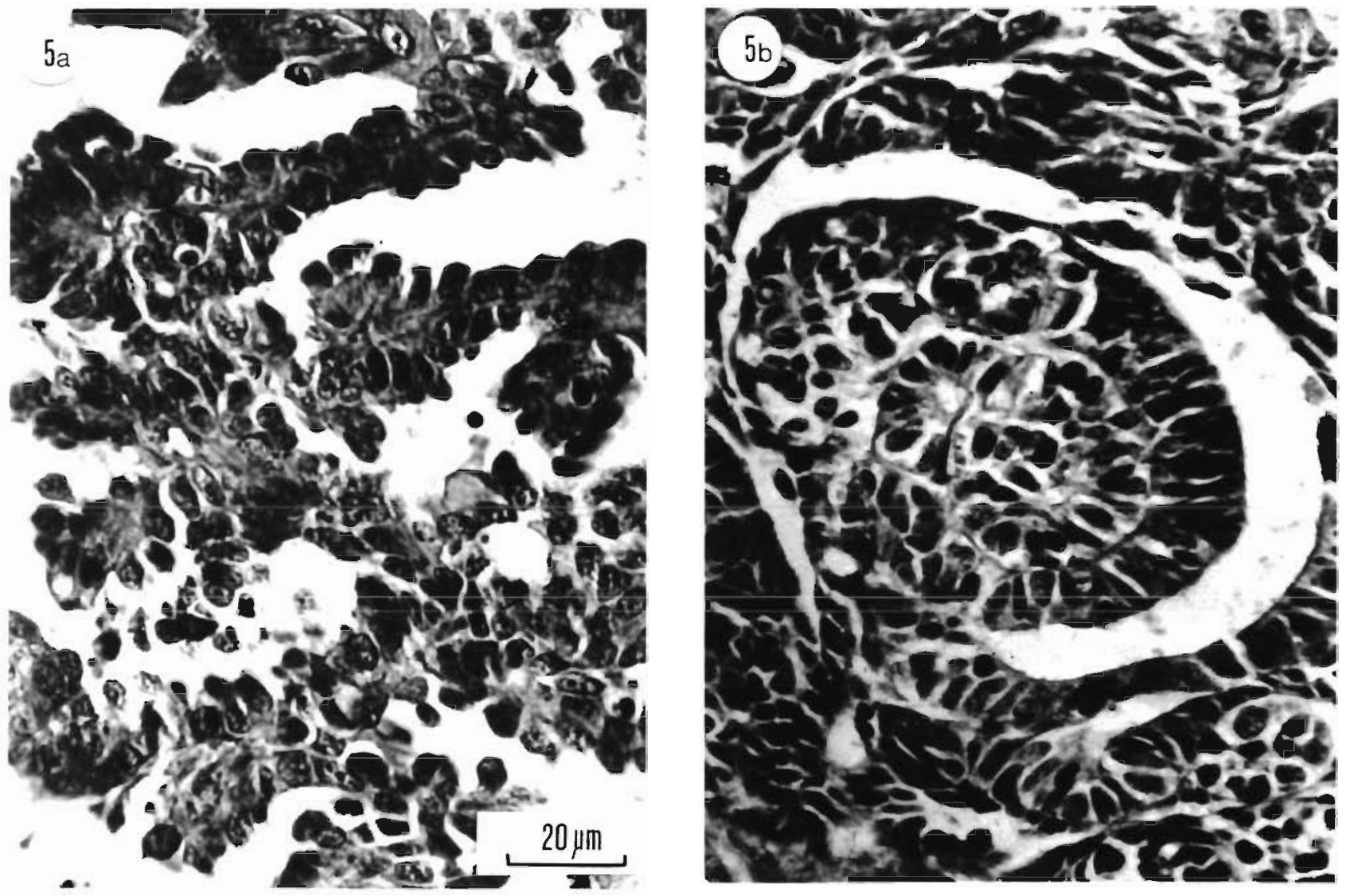

Fig. 5. Oncorhynchus mykiss. Epithelial component of nephroblastoma with sections of (a) papillary and (b) glomeruloid differentiation $\left(H \& E_{1} \times 400\right)$

is sometimes also referred to as embryonal miscellaneous tumour of the kidney. However, in the given case, we only observed the epithelial and mesenchymal components of sarcomatous appearance with no other structures which sometimes do occur in tumours of this kind, e.g. rhabdomyeloblastic, neuroblastic or cartilaginous structures.

Discussion. The structure of the tumour corresponds with cryptogenic nephroblastoma, described in the rainbow trout by the above-mentioned authors (Ghittino \& Dalforno 1971, Harshbarger 1972, 1973-1980, Odense et al. 1973). Referring to the description of nephroblastoma in striped bass Morone saxatilis with which Helmboldt \& Wyand (1971) stressed the characteristic stunted development of the glomerules, we would like to add that in our case, besides the tubular structures, there were also local suggestions of neoplastic glomerular formations. Unlike the above mentioned authors, we saw no cartilage in the tumour, though in the striped bass $90 \%$ of the tumour had been cartilaginous. A finding of cartilage in the nephroblastoma in the smelt Osmerus mordax is also mentioned by Huizinga \& Budd (1983). Like Odense et al. (1973), we observed the tumour to remain demarcated, with no signs of proliferation into the surrounding tissues. Neither did we see any haematopoietic tissue and melanin in the neoplastic tissue, which confirms what Ashley (1970) observed. However, traces of melanin were present in small fascia in the unaltered renal tissue which penetrated deep into the tumour. As distinct from what Odense et al. (1973) observed, we found no hyperaemia in the tumour, nor any haemorrhage and necrosis. Our finding is another case of absence of metastases in the rainbow trout, which is in contrast with the experience with nephroblastoma described so far in humans and other vertebrates.

\section{LITERATURE CITED}

Ashley, L. M. (1970). Pathology of fish fed aflatoxins and other antimetabolites. In: Snieszko, S. (ed.) A symposium on diseases of fishes and shellfishes. Special Publications No. 5. American Fisheries Society, Washington, D.C., p. $366-379$

Ghittino, P., Dalforno, S. (1971). Nephroblastoma spontaneo in trota irldea diallevamento (Salmo gairdneri). Riv. ital Piscic. Ittiopat. A VI(3): 69-72

Harshbarger, J. C. (1972). Work of the registry of tumours in lower animals with emphasis on fish neoplasms. In: Maw- 
desley-Thomas, L. E. (ed.) Diseases of fish. Symposium of the Zoological Society of London, No. 30, p. 285-303

Harshbarger, J. C. (1973-1980). Activities reports. Registry of tumours of lower animals. Smithsonian Institution, Washington. D.C.

Helmboldt, C. F., Wyand, D. S. (1971). Nephroblastoma in a striped bass. J. Wildlife Dis. 7. 162-165

Responsible Subject Editor: N. Peters, Hamburg, Germany
Huizinga, H. W., Budd, J. (1983). Nephroblastoma in the smelt, Osmerus mordax (Mitchill). J. Fish Dis. 6: 389-391

Odense, P. H., Logan, V H., Baker, S. R. (1973). Spontaneous nephroblastoma in a rainbow trout (Salmo gairdneri). J. Fish. Res. Bd Can. 30: 549-551

Manuscript first received: April 4, 1992

Revised version accepted: August 7, 1992 